\title{
Age-related association of aortic arch pulse wave velocity assessed by MRI with incident cardiovascular events: the multi-ethnic study of atherosclerosis (MESA)
}

\author{
Yoshiaki Ohyama ${ }^{1 *}$, Bharath Ambale Venkatesh', Chikara Noda ${ }^{1}$, Jang-Young Kim ${ }^{6}$, Yutaka Tanami ${ }^{1}$, \\ Gisela Teixido-Tura ${ }^{5}$, Atul Chugh ${ }^{7}$, Alban Redheuil ${ }^{4}$, Chia-Ying Liu², Colin O Wu ${ }^{8}$, Gregory Hundley ${ }^{3}$, \\ David A Bluemke², Joao A Lima'
}

From 19th Annual SCMR Scientific Sessions

Los Angeles, CA, USA. 27-30 January 2016

\section{Background}

The carotid-femoral pulse wave velocity (PWV) assessed by tonometry is predictive of future cardiovascular disease (CVD) events; however, the predictive value of aortic arch PWV assessed by MRI for CVD events has not been established in the general population. The aim of the present study was to evaluate the association of arch PWV with incident CVD events over 10 years based on the Multi-Ethnic Study of Atherosclerosis (MESA).

\section{Methods}

Aortic arch PWV was measured using through-plane aortic flow from phase contrast (PC) cine MRI at the level of the pulmonary artery bifurcation for transit time and black-blood sagittal images for transit length at baseline in 3,527 MESA participants free of overt CVD. Cox regression was used to evaluate the risk of incident CVD in relation to arch PWV adjusted for age, gender, race, and CV risk factors. Arch PWV were logarithmically transformed for COX regression models due to its rightskewed distribution (logPWV). There was significant interaction between arch PWV and age for outcomes, so analysis was repeated in each age decade (45-54, 55-64, 65-74, 75-84 years).

\section{Results}

At baseline, participants were $62 \pm 10$ years of age; 53\% women, 36\% White, 15\% Chinese, 29\% African American,

Table 1 Hazard Ratios of the logPWV for Cardiovascular Events Stratified by Age Groups no. of events

\begin{tabular}{|c|c|c|c|c|c|c|c|}
\hline & \multirow[t]{2}{*}{ no. of events } & \multicolumn{2}{|c|}{ Unadjusted } & \multicolumn{2}{|c|}{ Model 1} & \multirow{2}{*}{$\begin{array}{l}\text { Model } 2 \\
\text { HR }(95 \% \mathrm{Cl})\end{array}$} & \\
\hline & & HR (95\% Cl) & $p$ & HR (95\% Cl) & $p$ & & \\
\hline All participants $(n=3,529)$ & 427 & $1.26(1.16-1.38)$ & $<0.001$ & $1.06(0.97-1.17)$ & 0.21 & $1.03(0.94-1.14)$ & 0.46 \\
\hline Age categories & & & & & & & \\
\hline $45-54$ years old $(n-1,027)$ & 53 & $1.59(1.23-2.06)$ & $<0.001$ & $1.48(1.15-1.92)$ & 0.002 & $1.47(1.10-1.97)$ & 0.009 \\
\hline 55-64 years old (n-946) & 96 & $1.10(0.90-1.35)$ & 0.35 & $1.08(0.89-1.33)$ & 0.43 & $0.99(0.79-1.24)$ & 0.94 \\
\hline $65-75$ years old $(n-1,071)$ & 169 & $1.05(0.90-1.22)$ & 0.51 & $1.03(0.88-1.20)$ & 0.75 & $1.01(0.87-1.19)$ & 0.87 \\
\hline 75-84 years old $(n=485)$ & 109 & $0.94(0.78-1.14)$ & 0.55 & $0.95(0.78-1.15)$ & 0.56 & $1.00(0.83-1.22)$ & 0.98 \\
\hline
\end{tabular}

Hazard ratios are indicated per 1SD higher logPWV. Adjustment was performed for the following risk factors: model $1=$ adjusted for age, gender, and race; model 2 = model $1+$ mean blood pressure, antihypertensive medication use, diabetes, smoking, total cholesterol, HDL cholesterol, BMI. HR indicates hazard ratio; BMI, body mass index; HDL, high density lipoprotein; PWV, pulse wave velocity; logPWV, log-transformed PWV

${ }^{1}$ Cardiology, Johns Hopkins University, Baltimore, MD, USA

Full list of author information is available at the end of the article 
$20 \%$ Hispanic, and $45 \%$ had hypertension. The median value of arch PWV was 7.4 (IQR; 5.6 to 10.2 ) $\mathrm{m} / \mathrm{s}$. There were 427 CVD events over the 10-year follow-up. There was no significant association of PWV with incident CVD in all participants after adjustment for CVD risk factors. Stratifying by age groups, only 45-55-year-old participants had significant association of arch PWV with incident CVD in multivariable analysis (HR, 1.47; 95\% confidence interval (CI), 1.10-1.97; $\mathrm{p}=0.009)$, whereas other age groups did not (Table 1).

\section{Conclusions}

Aortic arch PWV assessed by MRI is a significant predictor of CVD events among middle-age (45 to 54 years old) individuals, whereas arch PWV is not associated with CVD among elderly in a large multi-ethnic population.

\section{Authors' details}

${ }^{1}$ Cardiology, Johns Hopkins University, Baltimore, MD, USA. ${ }^{2}$ National Institutes of Health, Bethesda, MD, USA. ${ }^{3}$ Wake Forest School of Medicine, Winston-Salem, MD, USA. ${ }^{4}$ Groupe Hospitalier La Pitié Salpêtrière Sorbonne Universités, Paris, France. ${ }^{5}$ Vall d'Hebron Hospital, Barcelona, Spain. ${ }^{6}$ Yonsei University, Seoul, Korea (the Republic of). ${ }^{7}$ Jewish Hospital, Luisville, KY, USA.

${ }^{8}$ National Heart, Lung and Blood Institute, Bethesda, MD, USA.

Published: 27 January 2016

doi:10.1186/1532-429X-18-S1-P132

Cite this article as: Ohyama et al:: Age-related association of aortic arch pulse wave velocity assessed by MRI with incident cardiovascular events: the multi-ethnic study of atherosclerosis (MESA). Journal of Cardiovascular Magnetic Resonance 2016 18(Suppl 1):P132.

\section{Submit your next manuscript to BioMed Central} and take full advantage of:

- Convenient online submission

- Thorough peer review

- No space constraints or color figure charges

- Immediate publication on acceptance

- Inclusion in PubMed, CAS, Scopus and Google Scholar

- Research which is freely available for redistribution

Submit your manuscript at www.biomedcentral.com/submit 